\author{
Xeno Rasmusson, Ph.D. \\ CSU, East Bay \\ Lydia Rodriguez, B.A. \\ City of San Leandro \\ Recreation and Human Services
}

\begin{abstract}
Background: The growing population of older adults will require specialized, adaptable and scalable services in order to maintain a quality of life. We offer an intergenerational and lifelong long learning model and provide guidelines for developing senior programming with relevance, accessibility and sustainability. Purpose: The aim of this work is to provide a framework for expanding and/or studying senior services. We also report on a preliminary needs assessment survey of older adults for the senior centers in their community. Method: A needs assessment questionnaire was developed and distributed to 56 men and women aged 50+ attending senior and/or community activities. Results: The vast majority $(82 \%)$ were satisfied with the activities and services offered by their local senior or community center and most (74\%) reported the cost was acceptable. Requested new activities included all-ages events, ukulele, scrap-booking, arts, and book clubs. Discussion: Centers looking to improve or increase senior programs should assess their local elders interests and needs. Delivering more varied activities to seniors could lead to numerous benefits, however, a number of real-world obstacles limit expanding senior services without increased cost. We recommend "senior centers" consider adding peermentors, and branching out to other ages, especially college students who have relevent skills and may need to volunteer for coursework or to explore career options.
\end{abstract}

Keywords: Successful Aging, Life-long Learning, Senior Services, Community Dwelling Elders

\title{
INTRODUCTION
}

Worldwide, between 1970 and 2025, we can expect the older population to increase by 694 million, or 223\% (Boultan-Lewis, Buys \& Lovie-Kitchin, 2006). In addition, "In 2025 there will be a total of 1.2 billion people over the age of 60" (World Health Organization [WHO], 2002, p. $6)$. With the rapid growth of seniors in mind, a great emphasis has been placed on the importance of senior activities. In the $21^{\text {st }}$ century, older adults in developed countries are more active and healthier than in prior years. The way senior programs are designed and marketed can aid in the maintenance and the continuing participation of older adults in senior activities or programs. However, many elders cannot not even dream of participating in these modern luxuries due to cost and transportation. Understanding what older adults want to learn and accomplish supports a contemporary view of elderhood, which may give facilitators the tools needed to transition into lifelong learning programs while serving the larger population of older adults on the horizon. We review and critique the popular developmental model of "successful aging" (e.g., Rowe \& Kahn, 1997) to support a compensatory framework for delivering enriching senior activities. 
Some older adults may feel that a "senior" program is not for them solely because of the stigma of "senior" in modern society; leaders might want to reconsider naming centers and programs based on input from those to whom it is being offered. For example, a younger older adult may not want to attend a program at a "Senior Center" because they may fear being stigmatized as a senior. For this reason many older adults could feel discouraged when attending senior activities and feel that senior programs or classes do not meet their specific needs or expectations. Finding ways that promote to both the younger older adult (55 to 75 years of age) and the senior population (75 and older) is critical to maintain participation within these programs. The purpose of this literature review is to: 1) Review the benefits that senior activities bring to older adults including social interaction, physical awareness, fitness and overall cognitive improvements. 2) Review the programs that the younger older adults could be drawn too, while continuing to provide programs to the senior population. 3) Review the importance of keeping these programs attainable to older adults of all economic and ethnic back rounds. Reviewing this literature can give facilitators a better understanding of how to transition senior programs into lifelong learning programs and to serve older adults on a larger scale.

\section{REVIEW OF LITERATURE}

Adult values and preference around learning as compared to many other activities and conditions such as work; social, spiritual, and emotional status; health; vision; home; life events; and demographic features were studied in 2645 older adults (Boulton-Lewis, et.al (2006). The results of multi-variate analysis indicated that learning and health were most important to elders. The younger older adult population or participants between the ages of 50-64 were more likely to be interested, need and want to learn new technology to keep up to date with potential late life employment as well potential for personal growth. Learning for older adults seems to be among their core needs and perhaps quite obviously, elders' needs are changing. An argument can made that older adults are not interested in learning new technology, in reality, to work in the $21^{\text {st }}$ century, older adults need tech skills. New technology also elders to stay in touch with loved ones, follow news, listen to music -- as a result, an entire field of Gerotechnology has emerged to understand and support how technology can reduce social isolation, increase cognitive stimulation and improve wellness in elders.

\section{Successful Aging: A Positive but Incomplete Developmental Model}

Some of the terms used throughout the literature include variations on "typical aging", "healthy aging", "successful aging", "active aging", "productive aging" or "robust aging" (See Restak, for an overview). Coined by John Rowe and Robert Kahn, successful aging however, is more than just a term to describe a positive outcome in older adulthood - sometimes it is used in a contracted form, "saging", as in "becoming sage." Successful aging was first presented a positive developmental model as early as the late 1970s. The key theoretical aspect of successful aging is that aging is not purely controlled by genetics; that is, we have some control over how we age based on our environment, lifestyle, self-care and leisure activity. Largely a model rather a theory, it has had different interpretations throughout the years.

Rowe and Kahn (1997) defined the outcome of "successful aging in terms of three components (a) low probability of disease and disease-related disability; (b) high cognitive and physical functional capacity; (c) and active engagement with life." Active aging has been presented by the World Health Organization report which states that "active aging" is the process of optimizing opportunities for health participation and security in order to enhance quality of life as people age" (p.12). The long accepted social disengagement theory explains the traditional aging deficit model as integral to the mutual desire to distance elders from society; that is, "aging" requires a withdraw or decrease in public activities and social interaction. 
However, healthy/active/robust/successful aging outcome are a strong counter to the deficit model and activity theory suggests the opposite. Activity theorists view successful aging as optimal aging that involves remaining active and continuing interpersonal relationships for as long as possible" (Duay \& Brian, 2006, p.423).

\section{Critique of Successful Aging Model}

A common critique that Duay and Brian (2006) points out that successful aging is just an outcome (or model), whereas something as simple as activity theory helps identify and enhance factors that lead to that outcome. Bowling and Dieppe (2005) focus on the idea that, "successful ageing needs to include elements that matter to elderly people" (p.1548) not the healthcare, housing or technology industries. In addition, their review suggests that although "Rowe and Kahn's model is the most widely used approach, it fails to address the implications of the fact that a disease-free older age is unrealistic for most" (p. 1549).

Bowling and Dieppe (2005) also surveyed nearly 1000 elders in the UK and the results implied that many viewed themselves as aging successfully; 75\% (631) rated themselves as ageing "Very well" or "Well" (as opposed to "Alright," "Not well" or "Not very well"). The results of the study implied that older adults had a wider range of idealisms and factors defining their own successful aging than the Rowe and Kahn model of Successful Aging. It is important to understand how these terms have evolved throughout the years in order to better serve all older adults but it is equally critical to ask older adults how they perceive successful aging and what activities they feel will make their aging more successful.

\section{Benefits of Senior Activities and Lifelong Learning Programs}

Many agree that the benefits of senior activities and lifelong learning programs are imperative when promoting successful aging for older adults. Many senior centers offer a wide variety of activities; adapted physical fitness training is a key to successful aging and found in nearly every community based senior center.

Dorgo, Robinson and Bader (2008) used the Short Form-36 to assess changes in self-reported physical, mental and social function in a group of older adults at a senior center who were trained by either same aged peer mentors or trained by qualified kinesiology student mentors. Dorgo, Robinson and Bader (2008) found that after a fourteen week period elders perceived physical, mental, and social functions improved significantly $(p<.05)$ for the peer mentored group but not for the kinesiology student trained group. Consequently the individuals who "participated in a physical fitness program with peer support perceived (a) overall improvement in physical and mental wellbeing (b) better social functioning, (c) enhanced ability to carry out physical and emotional roles, (d) improved general health and (e) increase level of vitality" (Dorgo, Robinson \& Bader, 2008, p.116). This research provides further evidence of the overall benefits of physical fitness programs for older adults but more importantly suggests the superiority of same-aged peer mentors. A number of recent studies have also reported excellent response among elders with university students doing internships as personal trainers.

Using a qualitative approach, Resnick, Vogel and Luisi (2006) reported on the Senior SelfEfficacy Pilot Program (SESEP). The purpose of the study was to explore what helped participants in exercise and barriers to the participant's willingness to exercise by way of indepth interview across a longitudinal health intervention study. Open-coding analysis found13 major themes and eleven of the themes focused on factors that facilitated participation in exercise. Some of those factors included physical and emotional benefits, external boost, social components, something new and different, rewards, goals and much more. One participant 
revealed that she felt she owed it to her group to show up to class. Commonly, the participants responded by saying that "it was fun" and made them laugh.

"Unpleasant sensations" was the key theme found as a barrier to exercise in the interviews (Resnick, Vogel \& Luisi, 2006, p.21). Shortness of breath, pain and fear were some of the unpleasant sensations however, learning how to manage the pain with exercise and rubbing the affected areas helped to keep the participants engaged in the exercise programs. Overall the results of the study provided a lot of qualitative data suggesting increased self efficacy among the participants who sustained their exercise.

Alders and Levine-Madori (2010) conducted a 12 week study was conducted to assess the benefits of art therapy in a senior center setting on cognitive performance. In this study, 24 elderly Hispanic/Latino individuals were evaluated using the Clock Drawing Test and the Cognitive Failures Questionnaire before and after the 12 week study period. Results showed that those who participated in the art therapy program improved more on the Clock Drawing Test and reported fewer cognitive problems compared to those who did not participate (p. 127). Alders and Levine-Madori (2010) note that previous research has suggested "that an active lifestyle paired with consistent, dynamic mental stimulation staves off cognitive impairment throughout the aging process" (p.128). While art therapy in general has been demonstrated to be effective in improving the participants' quality of life and in some cases cognitive abilities, other lifelong learning programs have also shown to be important to and effective for older adults.

Older adults are drawn to computers because of their need to keep connected to loved ones. Learning how to use e-mail and other social networks could enhance their connectivity at a minimal cost. Knowing these interests have encouraged case studiers related to computer use for older adults.

Saunders (2004) surveyed the opinions and attitudes that older adults have about using computers in order to develop a newly funded program to teach seniors how to use e-mail and the internet. Furthermore, the data gathered, aided in identifying "strategies to enhance computer use in senior citizen centers and maximize the connectivity of elders in their communities" (p.573). In addition, Saunders (2004) researches literature that implies that computer usage among older adults improves mental abilities and may decrease suicide rates by reducing the feeling of loneliness. Self-confidence, ability to learn, and memory retention were also noted as possible improvements for older adults.

Saunders (2004) results showed that many older adults felt scared to use computers because they were not properly trained and felt that having computer structured classes would be beneficial to them. Other findings concluded that vision impairments could also discourage computer use. Many did not use computers because they could not afford them. In addition, many of the participants had relatives who lived long distances and having access to the internet and a computer would allow them to stay connected. Others wanted to research information related to health issues. For all these reasons providing a lifelong learning program that teaches older adults how to use computers is imperative and may promote successful aging. With this information a facilitator could have a better understanding of some of the fears that older adults have regarding computers and potentially format a class that would address how older adults perceive computer use. 


\section{Developing and Providing programs for all older adults}

Recent studies have demonstrated a decline in "senior center participation". Some of the reasons included lack of transportation, and wanting to be around other individuals who are not categorized as being old and have poor health (Hooyman \& Kiyak, 2002).

Walker et al. (2004) further explores the reasons behind a decline in senior center participation in a study of eleven counties in the Nortex region of Texas. Data came from questionnaires completed by 289 senior participants and 14 senior center directors. Top activities reported were recreational, social and health related. Walker et al. (2004) concluded that among the respondents between 55 and 97 years of age the least active in senior center activities were the youngest age group 55-70. This suggests the need to market to the "youngold" population. Another clear factor in participation was transportation. Of those who participated in the senior activities, $94 \%$ of the participants lived 10 miles or less from the senior center.

Having shuttles that can transport individuals that are not in a close proximity of the centers would increase attendance for those individuals who are less mobile, frail or are unable to drive. Some other predictors of increased involvement included participation in a based faith activity and the group size of the activity. Another critical factor that has been studied and was replicated by Walker et al. (2004) is the underrepresentation of African American older adults within senior activities. Overall this study gives us an understanding of why participation has lessened and gives us ideas and methods which could increase participation among younger older adults, those who may not know about the programs, cannot afford the programs and those whom are less mobile. Increasing the participation of a diverse population in senior centers is should be a priority (Ntiri, 2010) and marketing to all older adults can result in successful aging for all older adults and reduce the healthcare burden for all.

\section{Affordability Revisited}

Narushima's (2008) evaluation of a senior day program found that from 2001 to 2003 the hourly cost for one program had increased by $115 \%$. While there are many benefits to lifelong learning programs and senior programs in general, it is also important to make these programs available to all older adults. Budget cuts and a growing elder population have impacted many centers that offer these programs. Many senior centers and adult education institutions have increased fees to try to sustain the programs or cut paid staff. Although the cost may seem low compared to commercial offerings, those who live on a fixed income may not be able to cover even low fees and may be forced to drop from the programs.

Narushima (2008) presents us with a literature review and a qualitative study that focuses on the benefits of lifelong learning programs and study of a 15 participants of a Canadian Senior Day Program. In-depth interviews found that "all 15 seniors clearly articulated their learning in the Seniors Day Program as a meaningful and valuable activity that 'kept them going' and 'kept them on their toes'” (Narushima, 2008, p. 681). Other results included that these seniors had also become politically aware of their right to learn. One of the participants of the study (Peter) stated:

"I am paying to this country from day one I came here. Even now, all my children grew up, I am still paying education taxes. I think it is very unfair to cut of seniors' programs. Because our income is limited, and our ability to move around is limited. If they reduce the fees more people could come." (p. 681)

These comments along with other seniors' responses suggest that is not only their need to learn, in fact it is there right to have attainable education. The purpose of the survey below is to 
illustrate the use of and responses to a needs assessment survey older adults about their usage and opinions about their local senior and/or community centers.

\section{Participants and Location}

\section{METHOD}

Of the 56 individuals who completed the questionnaire 8 did not participate in senior activities. The remaining 48 participated at senior activities offered at the San Leandro Senior Center, the Marina Community Center (SCC), Castro Valley Senior Center and the Ashland Senior Center. The majority (85\%) participated in programs offered by the SCC. The average age of the individuals who participated was 78 and $80 \%$ of the participants were women. 18 (37\%) of the participants had an annual household income of 30,000 or less. All the activities were offered to individuals who are 50 years and over. The eight non-participants attended local gyms, employees and relatives of employees who work for the City of San Leandro.

The participants attended a fall prevention class and a social activity (called Sunshine Seniors) located at the San Leandro Community Center, and a Zumba class offered at the Marina Community Center. Individuals who did not participate in senior activities were contacted via e-mail. San Leandro is a diverse community in the East Bay Region of San Francisco, California.

\section{Materials}

A brief (13 items) needs assessment and general experience questionnaire (see appendix A) was developed and presented to individuals aged 50 and over who participate in senior center activity(s). The goal was to obtain data that could be used to assess current activities offered at the San Leandro Community Center and other centers in the area. This instrument is also designed to obtain related information from individuals who currently do not participate in senior activities to examine needs and interests. As such this is more of an instrument for quality improvement rather than evaluation. The information could be useful to other Senior Centers within the East Bay and beyond. Collecting this data can also help in the recruitment of the younger adult population for volunteerism. Individuals were advised verbally that their participation was completely voluntary. The questionnaire included questions related to the activities they participated in or did not participate in, age, ethnicity, cost of activities, quality of activities, the obstacles that kept them from attending activities and transportation. Another question asking whether or not they felt their social physical health or well-being had improved was also included. An area for additional comments was available so that participants could give input on other activities they would like to see offered.

\section{Procedure}

The questionnaire was presented to participants in the beginning of the program or class while a verbal explanation was given, regarding confidentiality and their voluntary participation in the study. In addition individuals were advised that the data gathered would be shared with facilitators to hopefully improve the programs and activities being offered. Participants were allowed to take the survey with them and turn their questionnaires to the instructors. Questionnaires were collected directly from the instructor. Data was then entered into an excel sheet and the data was broken down by percentages to analyze the data of the participants and those who did not participate in a senior activity.

\section{RESULTS}

This self-report survey data indicated the participants felt that they had improved in their social, physical health and well-being. Fitness and social programs were attended the most with $26 \%$ of the participants reportedly attending those. When asked about the quality of the programs of those who responded (38) participants, 26\% felt the programs were outstanding, 
$31 \%$ felt the programs were above expectations, $16 \%$ felt the programs met their expectations and $18 \%$ felt the programs were below their expectations.

When asked to rate the cost, $29 \%$ of the participants felt the cost was outstanding, $16 \%$ felt the cost exceeded their expectations, $16 \%$ felt the cost met their expectations and $26 \%$ felt that cost was below their expectations (too expensive). Participants were also asked how they had learned about the programs and the majority, $40 \%$ of the participants said they became aware of the programs through the Recreation Activities Guide and 26\% found information about the programs through the city newspaper. The remainder of the participants were referred by a friend, family member or found the information in a flyer. Participants were also asked how they commuted to their activities and $75 \%$ of the participants said they drove their own car while the remainder of the participants used Paratransit or a subsidized shuttle service.

Barriers that kept individuals from participating in more programs included scheduling, being too busy, transportation and age qualifications (thought they were too young). Out of the 33 participants who responded to this question the most common barriers were: 15\% reported transportation as an obstacle, $42 \%$ reported being too busy as an obstacle and the remaining $43 \%$ of respondents felt that the time of day the programs were offered was an obstacle.

\section{Desired Activities}

Two of the participants suggested that they would be interested in activities related to legal advice and stock education seminars. The individuals who did not participate in senior activities wanted to see classes that were geared to individuals of all ages. Some of the suggestions included ukulele classes, a book club, a scrapbooking class, a photo managing class and an art history class. In addition those who did not participate in senior activities felt they were too young and busy to participate.

\section{Open-ended responses}

There were two areas where individuals were asked if they had any additional comments. In the first area participants were asked if they had additional comments related to the type of activity they engaged in. In the second area they were asked to mention any general additional comments. Some of the responses demonstrated their reasoning for their improved social well being while others described their improved physical/fitness well being.

One of the participants stated, "I live alone; coming to the senior community center makes my day. I exercise and make friends; also I took a review on computers. The center makes me happy." Other comments included, "I do not feel isolated meeting people is important to Me.", "I meet many nice people, get's me out of the house" and "I live alone, nice to be in company of other people."

Other comments related to health and fitness included "I had 5 artery bypasses. Doctor said that if I hadn't participated in an exercise program I would not have recovered so well". Some participants reported being more flexible, having better balance, increased body strength and becoming more aware of their age.

The results suggest that all of that all participants felt that their participation in the activities they attended had improved their social, physical health or well being. Some of the comments included statements like "I had 5 artery bypasses. Doctor said that if I hadn't participated in an exercise program I would not have recovered so well". Another participant stated "I live alone; coming to the senior community center makes my day. I exercise and make friends; also I took a review on computers. The center makes me happy." These statements represent the need for 
maintaining both fitness and social classes attainable. Also noting that that the majority of the participants had a household income of $\$ 30,000$ or less is important when addressing the cost of the activities and the programs offered.

\section{DISCUSSION}

With increasing budget cuts the inclination of many agencies who are trying to manage a budget is to increase the cost of programs. Another concern reported was related to transportation. The results showed that 25\% percent of the participants used a subsidized shuttle service such as Paratransit or the Flex shuttle. This number will inevitably get larger therefore assuring that funding for these programs is available is critical. While the majority of the participants felt content with the programs they participated in, the reality is that the San Leandro Senior Center caters to those who are 70 and over.

Based on the data retrieved from the younger older adults, they would be more inclined to participate in programs and activities if they were geared to individuals of all ages. Also two of the participants noted that naming the center a community center instead of a senior community center would possibly help attendance of the younger older adult. Understanding that there is wide range making up older adulthood that senior activities or programs need to serve can assist in developing programs that serve the larger population of older adults on the horizon.

There were of course some major limitations in this the study which should be modified in future needs assessments. First of all, a larger sample is essential for assuring that those we aim to serve have a voice as we assess their needs. In this case, allowing the participants to complete the questionnaires during the class time could have encouraged more individuals to complete the questionnaires. Also remaining in the classes as the participants completed the questionnaires could have lessened the number of unanswered questions. Finding a larger population of young-old adults is also necessary. Individuals in their 50's and 60's may benefit the most by stemming functional decline and by enjoying more years of enriching communitybased activities.

A major issue in this and all studies using convenience samples is the underepresentation of ethnic minority elders and elders with low income (see for example Ntiri , 2010). Nevertheless, the data reported in this study might suggest a few factors that might lead to more participation: different activities; free/cheap transportation; offer activities to a wider agerange; offered activities at different times of day. Such information could be useful to providers planning new programs and activities for adults. In addition, providers in various communities might collect similar local needs data that could be useful in planning for funding or applying for grants to maintain current services.

The literature suggests that the potential benefits of well-planned elder programs are endless. Physical, cognitive and social activities are notable in the literature as being vehicles to successful and active aging. Other key issues revolve around sustainability/affordability and the need to keep these programs accessible for all older adults. Although not easy, partnering with are colleges and high schools can create a pipeline of volunteers. Assuring that transportation is available and planning convenient scheduling are easy ways to improve community participation. Collecting this type of local information may help program facilitators serve older adults better on a larger and/or local scale. The diversity of older adults must be addressed at the local planning level. For example, going out to multicultural churches or posting information in doctor's offices could target the larger population of older adults that 
are not participating. We must serve those who ask, but also seek out those unable to ask for services.

\section{References}

Alders, A., \& Levine-Madori, L. (2010). The Effect of Art Therapy on Cognitive Performance of Hispanic/Latino Older Adults. Art Therapy: Journal of the American Art Therapy Association, 27(3), 127-135. Retrieved from EBSCOhost.

Boultan-Lewis, (2010) Education and Learning for the elderly Why, How, What, Educational Gerontology 36: 213228

Boulton-Lewis, G.M., Buys, L. \& Lovie-Kitchin, J. (2006) Learning and Active Aging, Educational Gerontology, 32: 271-2 82

Bowling A., \& Dieppe P. (2005) What is successful ageing and who should define it? British Medical Journal 331(753), 1548-1551

Duay. D., \& Bryan. V. (2006) Senior Adults' perceptions of successful aging, Educational Gerontology, 32: 423-445

Dorgo. S., \& Robinson. K., \& Bader. J., (2008) The effectiveness of a peer-mentored older adult fitness program on perceived physical, mental and social function. Journal of the American Academy of Nurse Practitioners (2009) 116122 .

Hooyman, N. R. \& Kiyak, A. H. (2002). Social gerontology: A multidisciplinary approach(6th ed.). Boston: Allyn and Bacon.

Narushima, M. (2008). More than Nickels and Dimes: The Health Benefits of a Community-Based Lifelong Learning Programme for Older Adults. International Journal of Lifelong Education, 27(6), 673-692. Retrieved from EBSCOhost.

Ntiri W. D. (2010). Recruitment Challenges: Lessons From Senior Center and Older African -African Participants in a Literacy Study. Educational Gerontology 36: 148-154.doi 10.1080/03601270903182869

Saunders, E. J. (2004). Maximizing Computer Use Among the Elderly in Rural Senior Centers. Educational Gerontology, 30(7), 573-585. doi:10.1080/03601270490466967

Resnick, B., Vogel, A., \& Luisi, (2006) Motivating Minority Older Adults to Exercise, Cultural Diversity and Ethnic Minority Psychology, 12(1), 17-29

Rowe, J.W. \& Kahn, R. L. (1997). Successful aging. The Gerontologist, 37(4), 433-440.

Walker, J., Bisbee, C., Porter, R., \& Flanders, J. (2004). Increasing practioners' knowledge of participation among elderly adults in senior center activities. Educational Gerontology, 30(5), 353-366.

World Health Organization (WHO). (2002). Active ageing: A policy framework. Retrieved August 3, 2011 from http://whqlibdoc.who.int/hq/2002/WHO_NMH_NPH_02.8.pdf 


\section{(APPENDIX A)}

\section{Senior Center Needs Assessment Questionnaire}

My name is Lydia Rodriguez and I am an undergraduate student in the Human Development department at Cal State East Bay. I am also the Customer Service Supervisor for the Marina Community Center and now the San Leandro Senior Community Center. For my Senior Research Project, I am conducting a survey of the usage of and needs for Senior Community Centers in the area. This research is being supervised by my professor, Dr. Rasmusson at Cal State East Bay. Please no te that your participation is completely voluntary and your responses will remain anonymo us. You may contact Dr. Rasmusson or me should you have any questions.

Please take a few minutes to complete this questionnaire. Your input is greatly appreciated and can hopefully help improve our community senior centers.

Contact Information:

Dr. Rasmusson

Lydia Rodriguez

Email: xeno.rasmusson@csueastbay.edu

Phone: (510) 301-2756

1. What's your age, gender and ethnicity?

Age, years:

$\square$ Male

$\square$ Female

$\square$ White

African American

Hispanic/Latino

Asian

Other:

2. What is your combined household income?

$\square$ Under 10,000 a year

Between 10,000 and 30,000

$\square$ over 30,000

3. Do you participate in activities at a Senior Community Center?

a) $\square$ Yes $\square$ No $\quad$ If yes in 3a, name of the

Senior Center:

b) If "no", do you participate in community-based activities geared for seniors:

$\square$ Yes $\square$ No

If yes in $3 b$, name of the Community-based Program or

Center:

If you participate, please complete 4-8. If you do not participate please skip to \#10 below.

4. What types of activities do you participate in?

$\square$ Health $\square$ Social $\square$ Fitness $\square$ Technical $\square$ Enrichment

Other, please list: 
5. Do you feel your participation in the activit ies have improved your social, physical health or emotional well being?

$\square$ Yes $\square$ No

Please explain your answer:

\section{For questions \#6 and \#7, please use the following Rating Scale:}

Below Expectations $=1$ Meets Expectations $=2$ Above Expectations $=3$ Outstanding $=4$

6. Rate overall quality

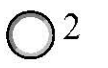

3

O

7. Rate overall cost:

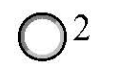

3

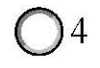

8. How did you find out about Senior Center activities?

$\square$ Newspaper $\square$ Flyer $\quad \square$ Activities Guide $\quad \square$ Friend

Other:

9. What type of transportation do you use when attending activities at the Senior Center?

Comments:

10. Are you aware of the activities and services offered at the Senior Center?

11. What prevents you from participating in more activities at the Senior Center?

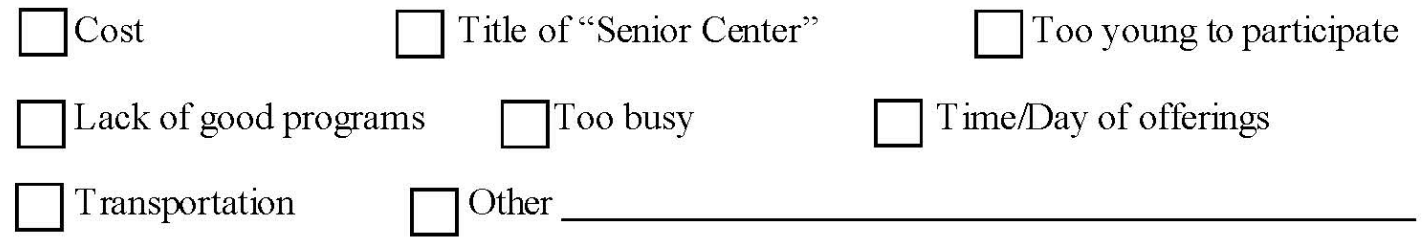

12. What activities or services would you like to see offered?

Comments:

13. Anything else you'd like to tell us about your experience or suggestions for Senior Center? Comments: 